\title{
REMOTE SENSING TECHNOLOGIES FOR LINEAR INFRASTRUCTURE MONITORING
}

\author{
P. D’Aranno ${ }^{1}$, A. Di Benedetto ${ }^{2}$, M. Fiani ${ }^{2 *}$, M. Marsella ${ }^{3}$ \\ ${ }^{1}$ Survey Lab S.r.l., Rome, Italy - peppe.daranno@ surveylab.info \\ ${ }^{2}$ Dipartimento di Ingegneria Civile, Università di Salerno, Fisciano (SA), Italy - (m.fiani, adibenedetto)@unisa.it \\ ${ }^{3}$ Dipartimento di Ingegneria Civile Edile e Ambientale, Università La Sapienza, Rome, Italy - maria.marsella@uniroma1.it
}

KEY WORDS: DinSAR, LiDAR, Infrastructures, Monitoring, Data processing, Correlation

\begin{abstract}
:
The need for a continuous evaluation of the state of preservation of civil infrastructures during their lifetime is increasingly requiring advanced monitoring technologies. The improvement of spatial and temporal resolution of the measurements is now one of the most significant achievement, especially for large infrastructures. Monitoring actions are necessary to maintain safety conditions by controlling the evolution of deformation patterns or detecting significant instabilities. Remote sensing technique such as Differential Interferometry by Synthetic Aperture Radar (DInSAR) allows identifying environmental vulnerability and potential damages on large road infrastructures thus contributing to plan and optimize maintenance actions. DInSAR data allow to highlight instability processes and to quantify mean deformation velocities and displacement time series. This information can be analysed considering geotechnical and structural characteristics and adopted to evaluate possible safety condition improvement and damage mitigation. Using proximal remote sensing techniques, such as Light Detection And Ranging (LiDAR), it is possible to analyse the pavement conditions on 3D models derived from a dense point cloud acquired by Mobile Laser Scanner (MLS). By combining the DInSAR and LiDAR datasets a great improvement is expected in the capability to promptly identifying critical situations and understanding potential risks affecting extended road infrastructures. The principal aim of this paper is to provide a general overview of the most innovative remote sensing techniques for infrastructure safety condition assessments. Furthermore, a methodological approach to define a reliable procedure for data processing and integration is applied on a test area located in the municipality of Rome.
\end{abstract}

\section{INTRODUCTION}

Monitoring large infrastructure networks and urban areas is a dominant socio-economic issues for the safety of the population (Arangio et al., 2014; Lan et al., 2012). Structures are threatened by the age of constructions and the evolution of natural and man-made ground deformation processes (Arangio et al., 2014). Traditional techniques provide measurements on a limited number of control points that are not usually enough to describe the overall deformation pattern. To guarantee a systematic and comprehensive control of structural stability over large areas, remote sensing technique (Laser Scanning) and satellite-based techniques can be effectively adopted (Marsella and Scaioni, 2018; Tapete et al., 2013).

The space technology used in this work is based on advanced DInSAR approaches (Ferretti et al., 2011; Ferretti et al., 2000; Lanari et al., 2004; Werner et al., 2003), that consists on the exploitation of SAR acquisition sequences collected over large time spans, allows providing useful information on both the spatial and the temporal patterns of the detected displacements through the generation of time series, with centimetre to millimetre accuracy (Bonano et al., 2013; Casu et al., 2006).

The DInSAR technology is an adequate alternative solution that can be fully assimilated within the ground-based monitoring. Monitoring civil infrastructure with InSAR is relatively new and currently not exploited to full advantage. The sheer amount of available data is acquired very frequently and with highprecision, at very low costs. These aspects makes it an attractive source of information (Chang et al., 2018). DInSAR technique is an extension of the InSAR technique and allows to measure sub-centimetric ground displacement, with an millimetric accuracy, using the phase difference between to SAR images acquires in different times over the same scene (Crosetto et al.,
2011). In particular, the variation of the interferometric phase can be represents from the sum of different quantities (Pepe and Calò, 2017), the interferometric phase contribution pertinent to the underlying topography has to be removed to measure only the interferometric phase term associated with the displacement. SAR is an active imaging sensor which can be mounted on board an aircraft or satellite, it uses microwaves therefore it has cloud-penetrating capabilities and it can be used efficiently in any meteorological condition with a full day-and-night operational capability (Chan and Koo, 2008). The SAR image contains a measurement of the amplitude of the radiation backscattered toward the radar by the objects (targets), amplitude depends on the roughness and the chemical composition of the targets on the surface. SAR technology mostly improved over the last decades (Gernhardt et al., 2010; Milillo et al., 2018), developing mainly methodologies based on the detection and monitoring of several geophysical phenomena (Alpers et al., 1981; Bürgmann et al., 2000; Massonnet and Feigl, 1998), such as the study of the dynamic of Earth's crust and the monitoring of the surface movements.

DInSAR deformation time series have been largely exploited in a wide variety of geophysical contexts, such as seismic, volcanic and mass movement scenarios, with a twofold goal: to map and monitor the detected displacements (Bovenga et al., 2013; Hilley et al., 2004; Lanari et al., 2010; Sansosti et al., 2010; Tizzani et al., 2009; Trasatti et al., 2008).

Besides, such remote sensing techniques have also demonstrated the capability to provide valuable information on the displacements affecting single buildings.

Structural and infrastructural health monitoring with DInSAR technique it is becoming one of the most powerful and economical means (Hooper, 2010). DInSAR observations from satellites are becoming more and more reliable for wide area 
and long-term deformation monitoring. The main contribution of this technique is the exploitation of a large number of observed point displacements, distributed along the whole structure.

The first applications in the infrastructural field date back more than two decades ago. Ying and Qinfen (1995) presented a region-based method for the recognition of roads and bridges in fully polarimetric SAR images. Hough transform to find potential bridge fences and to recognize roads was used. Morphological filtering was used to suppress speckle in SAR images. Soergel et al. (2008) have extracted key features of the bridge's geometry from the complementary data sources, to determine the water level, smooth the noisy InSAR DEM (Digital Elevation Model) data on water surfaces, in order to generate an improved 3-D visualization of the scene.

Terranova et al. (2015) presented a DinSAR analysis and review of ERS and Radarsat data on the city of Napoli (Italy). These data was processed using the Persistent Scatterers Interferometric synthetic aperture radar (PSInSAR) technique. They have been identified five main areas of subsidence affecting residential districts and strategic infrastructures.

Rail transport is an enabler of economic progress, used to mobilise goods as well as people. Therefore, railway tracks monitoring is of fundamental importance to ensure the track quality in both the construction phase and the regular maintenance stage (Chen et al., 2018). DInSAR technique allowed the detection of previously unknown settlement in several stretches of two major railway lines of NE Spain (Castañeda del Álamo et al., 2015). The area affected by subsidence was detected through the analysis of archived data of the ENVISAT and ALOS SAR missions. The results showed that DInSAR methods allow deformation of railways to be identified and monitored, that may otherwise compromise both serviceability and safety.

Qin et al. (2018) have investigated long-term subsidence mapping over the entire transportation network of Shanghai (more than $10,000 \mathrm{~km}$ ), demonstrating that SAR data can provide useful information for management and maintenance. The elevated roads, ground highways and underground subways were analysed.

Ruiz-Armenteros et al. (2018) showed the potential SAR data for monitoring deformation of one earth-fill dam. The researchers said that deformation detected might be assumable for this kind of dams.

Thanks to the development of high resolution SAR sensors many permanent scatterers can be found in one individual infrastructure in order to properly discover various types of deformation movements. Furthermore, a shorter revisit times guarantee a long series of SAR data so to account for a seasonal expansion due to changes in water level and/or temperature (Bakon et al., 2014).

Temperature variation is just as important in the analysis of long-term structural behaviour of civil infrastructures. Thermal dilation mapping and characterization was analysed using DinSAR tecnique (Qin et al., 2018). The results were verified in terms of the estimated linear thermal dilation coefficient. The analysis was based on two main steps: a pre-analysis was adopted to obtain the thermal transmission direction, then the regression analyses were performed to estimate the thermal dilation model.

Akin to RADAR technology, LiDAR acquire details by illuminating an target using light from the near-infrared region (about $1.0 \mu \mathrm{m}$ ) and it is based on two principles: Time-OfFlight (TOF) and Phase Shift (PS). TOF sensors are based on the measure of the travel time between the transmission of the signal and its reflection. The PS sensors are based on the measurement of the angular offset between the emitted and the reflected signal.

Laser scanner technique is based on LiDAR technology and nowadays it is very used for deformation monitoring of different applications: architecture, civil engineering, industry and archaeology (Schulz, 2008). The laser scanner technique allows a fast collection of enormous volumes of highly dense, irregularly distributed, accurate geo referenced data, in the form of three dimensional (3D) point clouds. The resultant point cloud is then post-processed to extract roadside feature data including pavement and roadsides in order to gather data for asset management, as-built documentation, and maintenance operations (Guan et al., 2016). In Highway and especially in airport the evaluation of road pavement performance is essential for effective maintenance design engineering (Barbarella et al., 2018; Barbarella et al., 2017). The research is oriented towards the study of survey methods in order to obtain increased safety, higher data collection speed, higher accuracy data, and minimising traffic interference (Ragnoli et al., 2018; Yen et al., 2011).

The 3D laser scanner technology has high potential to collect reliable road profiles, moreover it is possible to visualize the pavement roughness covering the entire pavement (Chang et al., 2006). Terrestrial Laser Scanning (TLS) point clouds were often used to build roughness maps of the pavement surface through quarter-car model simulation over a 3D mesh grid (Alhasan et al., 2017). Especially interesting are Mobile Laser Scanner (MLS) systems, they allow for the acquisition of point cloud by means of one or more scanners that are mounted on a mobile platform (vehicles, boats, trains) (Guan et al., 2016; Williams et al., 2013). This technique reduces costs and acquisition times compared to traditional techniques. The data collected were used for a number of geometric analyses including curve layouts, lane marking extraction, slope analysis, drainage properties, bridges height, lane width and automatic classification of urban ground elements (Balado et al., 2018; Gargoum et al., 2018; Prochazka et al., 2018; Yadav et al., 2018). In addition, MLS data were used to evaluate pavement condition (Kumar and Angelats, 2017) as rutting, ride comfort, texture, and automated distress detection.

Recently, novel strategies combining advantages of existing fusion techniques were proposed. Some results show that analysis of combined InSAR and LIDAR data can provide an improvement in DEMs (Gamba et al., 2003). Moreover, it is possible to exploit a LiDAR DEM to improve to extent the 2D and 3D representation of buildings extracted by phase unwrapping from InSAR measurements. The researchers also proposed a simple way to exploit LiDAR data in the area of interest, especially when the whole area is not covered (Gamba et al., 2006). Anghel et al. (2016) showing that the estimated deformations using the SAR data were in good agreement with available in-situ data provided through laser scanner surveys and embedded measuring systems.

Currently there are a great amount of data in the ESA archive derived from ERS - ENVISAT SAR missions that must be exploited. These data allow to reconstruct the historical displacement of a structure in the last 20 years. Furthermore, the operative SAR mission such as Sentinel 1 and Cosmo Sky-med (for high resolution information) allow to develop a long time monitoring.

In this paper we analyse 3D data acquired from multi-temporal Laser Scanner surveys in order to compare the results with displacements obtained through DinSAR analysis. 


\section{METHODS}

\subsection{DInSAR data collection and analysis}

Satellite remote sensing is a technique that allows the generation of high-resolution images, by processing the magnitude and the phase of a reflected signal on the ground and sent by the antenna. By exploiting the echo of the signal, it is possible to obtain the effects of an extremely large antenna (with a wave of the order of kilometer) synthesizing it in a few meters (Bonano et al., 2012; Manunta et al., 2008; Marsella et al., 2015; Scifoni et al., 2016; Zeni et al., 2011).

An interferogram can be obtained from the difference between sequences of acquisitions and it provides information on the displacements of the observed surface according to the phase.

This technique has the potential to detect millimetric target displacements along the Line-Of-Sight (LOS) direction, allowing to measure mainly the variations in the altimetric component.

The results of a multi-temporal analysis using a stack of interferograms can be organized in a database and embedded within a GIS environment for visualization and analysis. For each measurement point, the database can contain:

- The position on the ground, that means the geographic coordinates;

- The average annual displacement speed (measured in the sensor view direction), expressed in $\mathrm{mm} /$ year;

- The historical displacement series, that is a series of values that represents, acquisition by acquisition, the evolution of displacement of the measurement points, expressed in $\mathrm{mm}$ and measured in the sensor view direction;

- A quality parameter (coherence), normalized between 0 and 1: the closer it gets to 1 , the more the measurement point has optimal characteristics for the analysis.

In this way, it is possible to represent measured points and the related information on aerial or satellite orthophotos or vector maps to proceed to additional analysis and to integrate them with other monitoring data, such as those derived from structural and geotechnical investigations.

To analyse the behaviour of the infrastructure or detect potential damages it is useful to apply an interpolation where the information shifts from punctual and discrete to spread and continuous. A geostatistical analysis can be performed to obtain an assessment of the displacement spatial variability in order to obtain a more reliable estimation of the magnitude of the settlements from interpolated data. In this way, it is possible to obtain continuous information that allows, through a coloured scale, to show the overall trend in a certain area. By interpolating the cumulative displacements of the DInSAR data (Scifoni et al., 2016), it is possible to determine the cumulative yields along sections to highlight settlements or irregular shapes.

\subsection{LiDAR data collection and analysis}

The LiDAR technology has high potential to collect data usable to build 3D models of the road surface. The survey on the test site was carried out with both a MLS and a TLS in order to compare the results.

Whereas the mobile systems (MLS) provide a point cloud directly georeferenced in a coordinate system (in Italy UTM/ETRF00), the stationary TLS measurement require a post- processing. In better details, the TLS acquires the spherical coordinates of the object points referred to the centre of the instrument. Therefore, all the scans must be co-registered and aligned, then the global point cloud must be georeferenced.

Afterwards, both point clouds derived from the two laser systems has been processed in order to extract the road surface. The first step aimed to edit the laser data in order to extract only the point cloud belonging to the road surface. The method we have followed is based on the M-estimator SAmple Consensus (MSAC) algorithm, which is a robust variant of the Random Sample Consensus (RANSAC) algorithm, an iterative method to estimate parameters of a mathematical model from a set of observed data that contains outliers (Torr and Zisserman, 1996). Point cloud filtering into ground and non-ground points was carried out implementing an algorithm in Matlab, based on the building of a 3D grid. A sphere with a given radius and center in each grid node was built. The points inside the sphere were fitted on the best-fit plane using the MSAC algorithm.

Moreover, since a rectangular grid DEM is not suitable to model a road surface since its paths is curvilinear and its length is significant, an algorithm able to generate a grid DEM with curvilinear abscissa (corresponding to the central road axis) was implemented. For the interpolation, the Inverse Distance Weighting (IDW) method was used (Yang et al., 2004). The grid step has been related to both density and geometry of point patterns (Hengl, 2006). Such a DEM consists of a rectangular matrix of heights in which the rows represent the cross-sections and the columns the longitudinal profiles.

\subsection{Correlation}

In order to make a comparison between DiNSAR and LiDAR, for both datasets the cumulative displacements were computed and then the existence of correlation between them has been evaluated.

As for LiDAR, since the grid interval and its origin is the same for all the DEMs built with data surveyed over time, the cumulative displacements have been computed as matrix differences of the height values along the rows (cross sections). For the comparisons with DInSAR, we took into account a cross-section every $50 \mathrm{~cm}$, so to cover a size that is twice the pixel of the DinSAR image (about $3 \mathrm{~m}$ ).

As for DinSAR, a polynomial curve was fitted to the set of cumulative displacements to obtain a continuous function. Starting from the equation of the curve, the displacements in correspondence with the nodes of the cross sections derived from LiDAR DEMs have been determined.

Finally, to assess if the data by DinSAR and LiDAR are correlated, the Pearson correlation coefficient has been computed; it gives a measure of the linear correlation between two variables :

$$
r_{x y}=\frac{\sum_{i=1}^{n}\left(x_{i}-\bar{x}\right)\left(y_{i}-\bar{y}\right)}{\sqrt{\sum_{i=1}^{n}\left(x_{i}-\bar{x}\right)^{2}} \sqrt{\sum_{i=1}^{n}\left(y_{i}-\bar{y}\right)^{2}}}
$$

where:

$\mathrm{n}$ is the sample size;

$\mathrm{x}_{\mathrm{i}}, \mathrm{y}_{\mathrm{i}}$ are the individual sample points indexed with $\mathrm{i}$

$\bar{x}=\frac{1}{n} \sum_{i=1}^{n} x_{i}$ (the sample mean); and analogously for $\bar{y}$ 
The coefficient is the ratio of the covariance between the two variables to the product of their standard deviations. Pearson's correlation coefficient is a statistical measure of the strength of a linear relationship between paired observations. It assumes a value between +1 and -1 and the closer the value is to 1 or -1 , the stronger the linear correlation. We can describe the strength of the correlation using the guide that Evans (1996) suggests for the absolute value of $r_{X Y}$ : up to 0.59 the correlation is 'moderate', between 0.60 and 0.79 is 'strong', between 0.8 and 1 the correlation is defined 'very strong'.

\section{RESULTS}

\subsection{Data set}

The analysis was carried out on a stretch of road of southern Rome, where a DInSAR Cosmo-SkyMed dataset was available for the period between July 2014 and February 2017.

Figure 1 shows the test area; DInSAR data are available in the area enclosed within the yellow rectangle (panel a). Panel b) shows the scatter plot of the targets whereas in panel c) the displacement map is shown. Panel d) shows the cumulative displacements computed in correspondence of the section AA'.

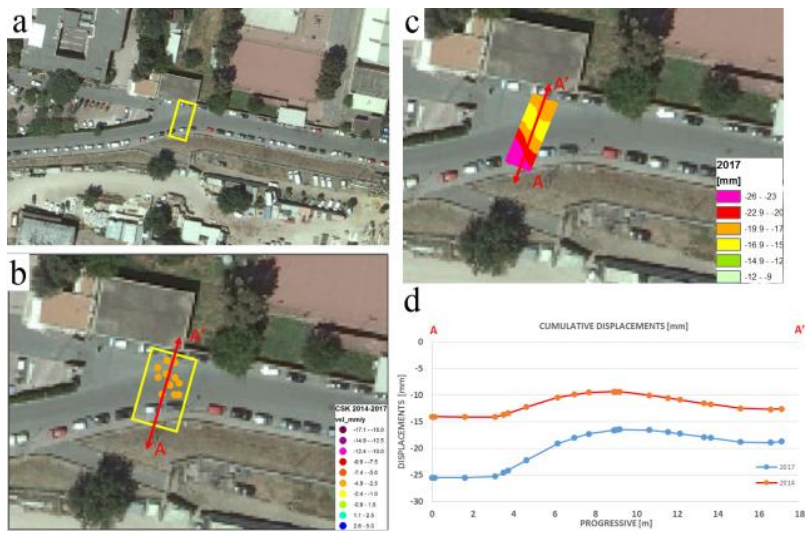

Figure 1. Test area

Two TLS instruments, a Ilris $3{ }_{6} \mathrm{D}$ by Optech and a Riegl VZ400 by Riegl were used to acquire the scans. Both instruments (TOF type) are characterized by long range, good accuracy (approximately 5mm@50m) and high-speed acquisition. A few of well spread spherical targets, made of high-reflectance polymer material with $15 \mathrm{~cm}$ diameter, were used both to coregister the TLS scans and georeference the aligned point cloud. The coordinates of the target centers were derived from a GNSS (Global Navigation Satellite System) survey. A reference station (master) was materialized near the test area and connected through static baselines with three permanent stations (PS) within up to about $10 \mathrm{~km}$. These PS (MOSE, INGR and ROAN) are belonging to the national geodetic CORS (Continuously Operating Reference Stations), framed in the Italian geodetic and cartographic System UTM/ETRF00. Target coordinates were measured connecting the target points with the master station (about $100 \mathrm{~m}$ apart) through fast-static baselines.

The CloudCompare v.9 software was used to co-register the point clouds and align them to obtain a global point cloud. Then, it has been georeferenced with a six-parameters similarity transformation using the software package PolyWorks v.14 by InnovMetric. The maximum density of the point cloud was about 35000 points $/ \mathrm{m}^{2}$, the minimum density was about 500 point $/ \mathrm{m}^{2}$.

MLS data were acquired by a Riegl VMX-450 laser scanner mounted on the roof of a vehicle driven along the stretch of road. The roof-carrier mounted measuring head integrates two RIEGL VQ-450 laser scanners, which are symmetrically configured on the left and right sides, pointing toward the rear of the vehicle at an angle heading of approximately $145^{\circ}$, as well as inertial measurement and GNSS equipment, housed under an aerodynamically-shaped protective cover. Such a configuration is called 'Butterfly' or ' $\mathrm{X}$ ' pattern. The main characteristics of the MLS system are: line scan speed up to 400 lines / sec (1.1 million points per second $)$, precision = $5 \mathrm{~mm}$, accuracy $=8 \mathrm{~mm}$. The vehicle was traveling at a speed of about $50 \mathrm{~km} / \mathrm{h}$. The point density is about 8000 point $/ \mathrm{m}^{2}$.

Figure 2 shows the layout of the thirteen cross-sections extracted from the DEM used for Pearson's coefficient computation.

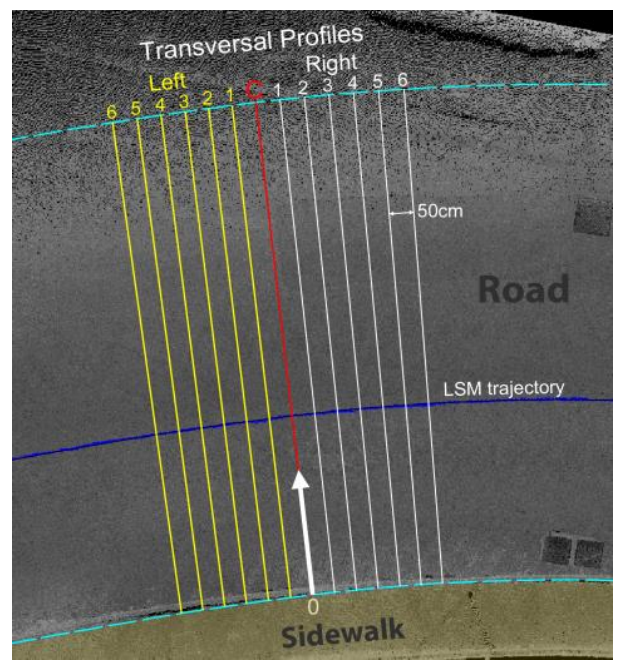

Figure 2. Cross sections extracted from LiDAR DEMs

\subsection{Integrate analysis}

Figure 3 shows the fourth degree polynomial curve fitted to the set of DinSAR cumulative displacements. The function fitted the data very well. High order polynomials can be highly oscillatory but with fourth order polynomials, the curve is more likely to fall near the midpoint. The goodness of fit was measured with the $\mathrm{R}^{2}$ coefficient of determination, very close to 1 .

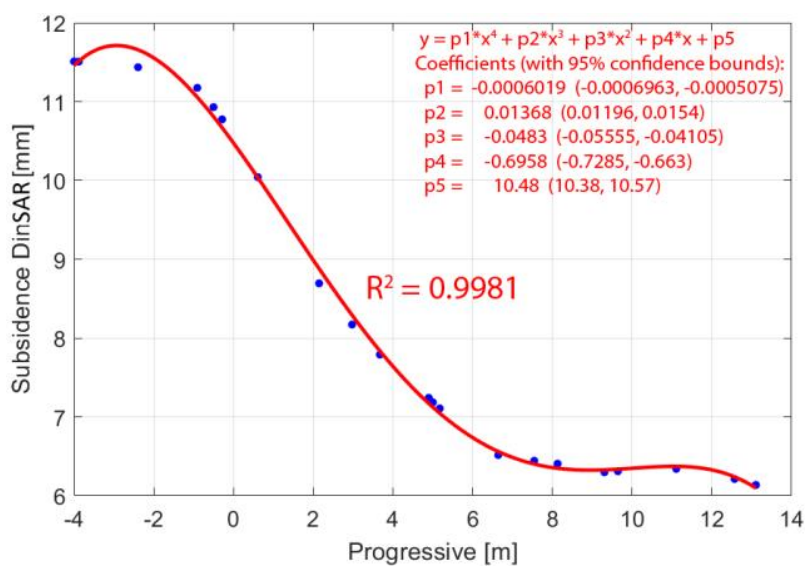

Figure 3. Fitted cumulated DInSAR displacements (31 months) for cross-section C in Figure 2 
Figure 4 shows the scatter diagrams of Pearson correlation coefficient computed for each considered cross section line.

The Pearson's correlation coefficient for these variables, in most cases, is greater than 0.80 , showing a very high positive correlation; the LiDAR displacements increase as the values of DInSAR displacements increase.

Subsidence DInSAR [mm]
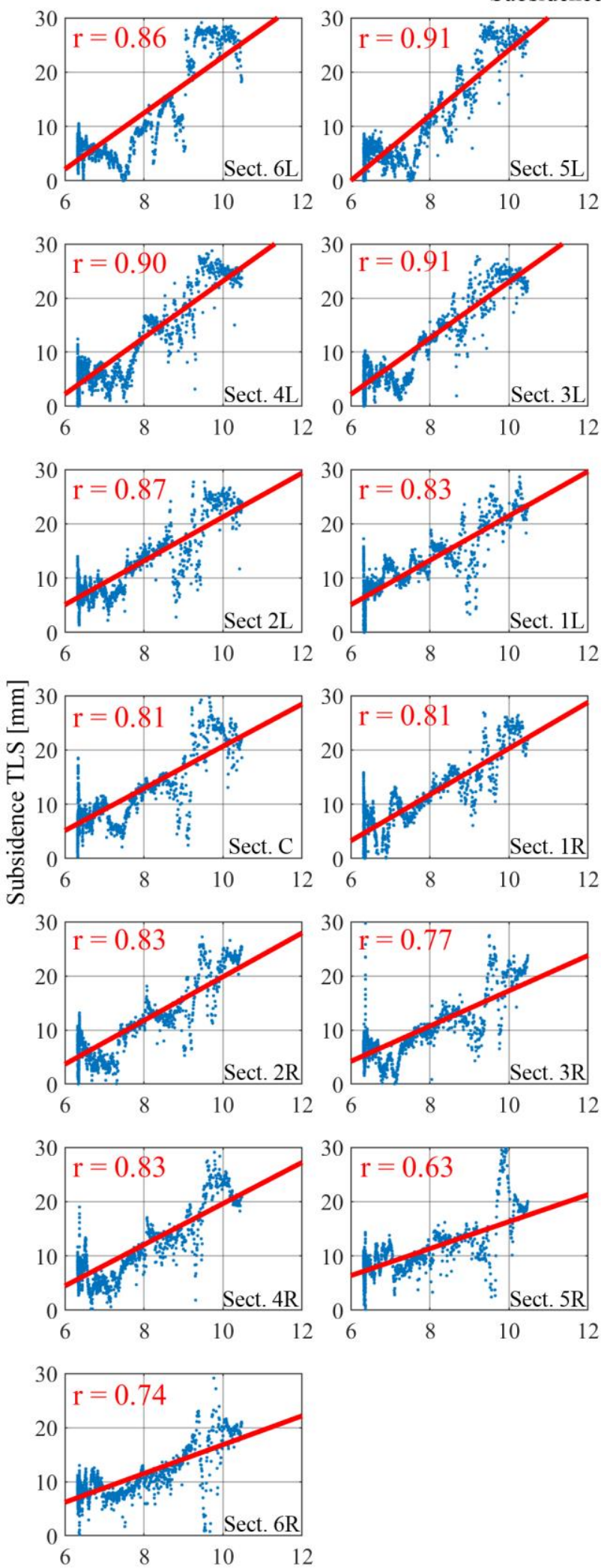
between them.
Nonetheless, this high correlation value does not mean that the displacements agree; the coefficient (r) measures the strength of the correlation between two variables, not the agreement
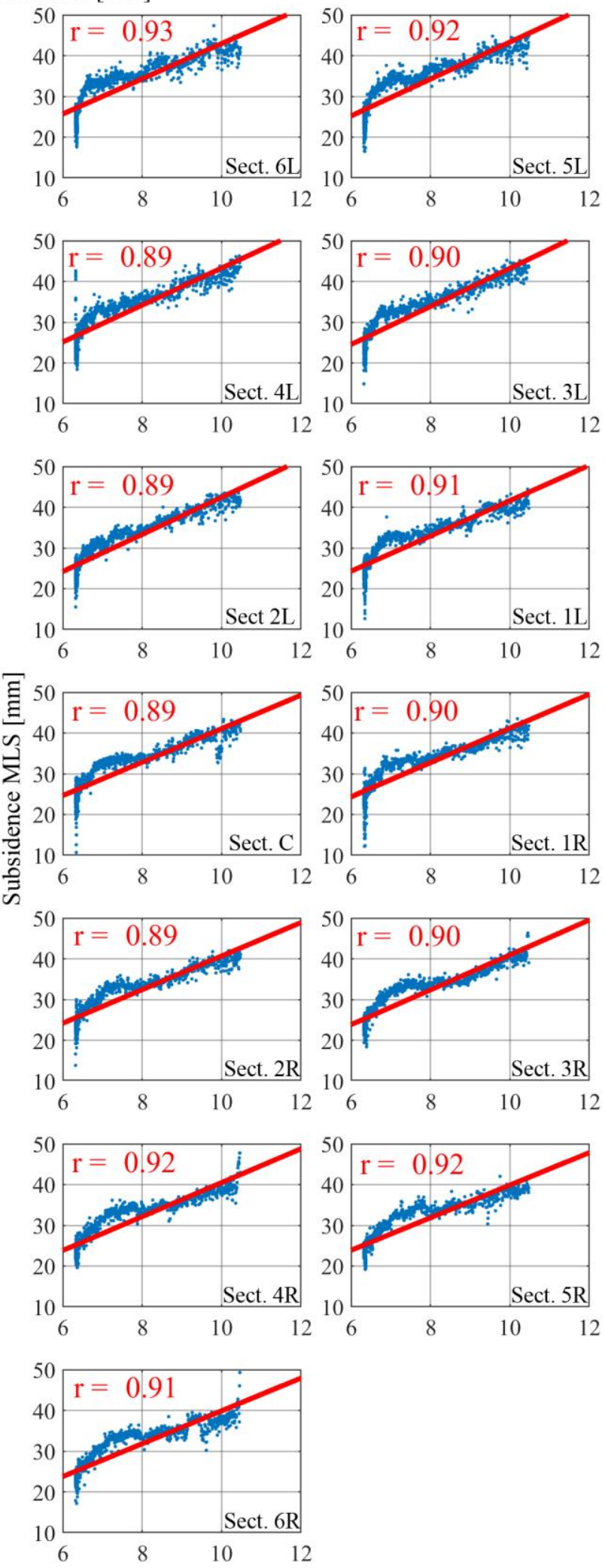

Figure 4. Scatter plots and correlation coefficients between the displacements observed with DinSAR and LiDAR techniques 
The agreement is verified only if the points in Figure 4 lie along the regression line (red line in figure), but this will not happen because the resolutions and accuracy of the two techniques are different.

It is mandatory to analyse first of all the scatterplot, i.e. the point distribution in correlation diagrams, to verify if a linear relationship exists. Even if the correlation coefficient value is high, indication of a strong correlation, not necessarily the correlation is linear.

By observing the trend of the regression line, the displacements obtained with the DInSAR technique are underestimated. Finally, the TLS displacements show better agreement with the DInSAR ones. This is probably due to the many different sensors used in MLS for directly georeferencing data (i.e. GNSS, IMU, DMI). GNSS systems are used in LiDAR to compute the trajectory of the sensor so it is important to keep in consideration the most common related positioning errors. Other sources of errors are mainly related to the inertial measurement unit (IMU) system.A number of tests showed that the accuracy of MLS as for height component (at 95\% confidence level) ranges between 2.9 and $3.1 \mathrm{~cm}$ (Puente et al., 2013). These values are in agreement with the differences obtained with the two LiDAR techniques. The correlations with LSM displacements seem stronger, the data are less dispersed; this is mainly due to the lower resolution and density than the TLS data.

\section{CONCLUSIONS}

The paper provides an overview of two relative new satellite and ground based remote sensing techniques useful for assessing infrastructure safety condition.

DInSAR has been successfully used for generating large-scale surface deformation maps with a great accuracy whereas LiDAR is useful to collect data with adequate accuracy and high resolution for mapping and inventory purposes. In particular, LiDAR has been used to assess pavement geometric characteristics, becoming an excellent source of data for pavement assessment and maintenance, also because the surveyors are able to collect data safely with minimal interruptions to traffic flow.

It follows on that a synergistic use of remote sensing technologies would be advantageous for monitoring large linear infrastructure since a combination of the two methods allows to collect information at different temporal and spatial scale.

In order to verify the coherence of the data, a correlation analysis was performed on a test area. The results demonstrated a meaningful relationship between the cumulated displacements computed with data coming from the two techniques. TLS displacements show a better agreement with the corresponding coming from DInSAR than MLS ones.

In order to improve safety infrastructure, the next step is to study new operating procedures for a reliable integration of different remote sensed data, together with the assessment of accuracy of the study results.

\section{REFERENCES}

Alhasan, A., White, D.J., De Brabanter, K., 2017. Spatial pavement roughness from stationary laser scanning. International Journal of Pavement Engineering, 18, 83-96.
Alpers, W.R., Ross, D.B., Rufenach, C.L., 1981. On the detectability of ocean surface waves by real and synthetic aperture radar. Journal of Geophysical Research: Oceans, 86, 6481-6498.

Anghel, A., Vasile, G., Boudon, R., d'Urso, G., Girard, A., Boldo, D., Bost, V., 2016. Combining spaceborne SAR images with 3D point clouds for infrastructure monitoring applications. ISPRS Journal of Photogrammetry and Remote Sensing, 111, 45-61.

Arangio, S., Calò, F., Di Mauro, M., Bonano, M., Marsella, M., Manunta, M., 2014. An application of the SBAS-DInSAR technique for the assessment of structural damage in the city of Rome. Structure and Infrastructure Engineering, 10, 14691483.

Bakon, M., Perissin, D., Lazecky, M., Papco, J., 2014. Infrastructure Non-linear Deformation Monitoring Via Satellite Radar Interferometry. Procedia Technology, 16, 294-300.

Balado, J., Díaz-Vilariño, L., Arias, P., González-Jorge, H., 2018. Automatic classification of urban ground elements from mobile laser scanning data. Automation in Construction, 86, 226-239.

Barbarella, M., D’Amico, F., De Blasiis, M., Di Benedetto, A., Fiani, M., 2018. Use of Terrestrial Laser Scanner for Rigid Airport Pavement Management. Sensors, 18, 44.

Barbarella, M., De Blasiis, M.R., Fiani, M., 2017. Terrestrial laser scanner for the analysis of airport pavement geometry. International Journal of Pavement Engineering, 1-15.

Bonano, M., Calò, F., Manunta, M., Marsella, M., 2012. The SBAS-DInSAR technique: A tool for deformation monitoring in the urban damage assessment, Life-Cycle and Sustainability of Civil Infrastructure Systems: Proceedings of the Third International Symposium on Life-Cycle Civil Engineering (IALCCE'12), Vienna, Austria, October 3-6, 2012. CRC Press, p. 395.

Bonano, M., Manunta, M., Pepe, A., Paglia, L., Lanari, R., 2013. From Previous C-Band to New X-Band SAR Systems: Assessment of the DInSAR Mapping Improvement for Deformation Time-Series Retrieval in Urban Areas. IEEE Transactions on Geoscience and Remote Sensing, 51, 19731984.

Bovenga, F., Nitti, D.O., Fornaro, G., Radicioni, F., Stoppini, A., Brigante, R., 2013. Using C/X-band SAR interferometry and GNSS measurements for the Assisi landslide analysis. International Journal of Remote Sensing, 34, 4083-4104.

Bürgmann, R., Rosen, P.A., Fielding, E.J., 2000. Synthetic Aperture Radar Interferometry to Measure Earth's Surface Topography and Its Deformation. Annual Review of Earth and Planetary Sciences, 28, 169-209.

Castañeda del Álamo, C., Galve, J.P., Gutiérrez, F., 2015. Railway deformation detected by DInSAR over active sinkholes 
in the Ebro Valley evaporite karst, Spain. Nat. Hazards Earth Syst. Sci., 15, 2439-2448.

Casu, F., Manzo, M., Lanari, R., 2006. A quantitative assessment of the SBAS algorithm performance for surface deformation retrieval from DInSAR data. Remote Sensing of Environment, 102, 195-210.

Chan, Y.K. and Koo, V.C., 2008. An introduction to synthetic aperture radar (SAR). Progress In Electromagnetics Research, 2, 27-60.

Chang, J., Chang, K., Chen, D., 2006. Application of 3D Laser Scanning on Measuring Pavement Roughness. Journal of Testing and Evaluation, 34, 83-91.

Chang, L., Dollevoet, R.P.B.J., Hanssen, R.F., 2018. Monitoring Line-Infrastructure With Multisensor SAR Interferometry: Products and Performance Assessment Metrics. IEEE Journal of Selected Topics in Applied Earth Observations and Remote Sensing, 11, 1593-1605.

Chen, Q., Niu, X., Zuo, L., Zhang, T., Xiao, F., Liu, Y., Liu, J., 2018. A Railway Track Geometry Measuring Trolley System Based on Aided INS. Sensors, 18, 538

Crosetto, M., Monserrat, O., Cuevas, M., Crippa, B., 2011. Spaceborne Differential SAR Interferometry: Data Analysis Tools for Deformation Measurement. Remote Sensing, 3, 305.

Evans, J.D., 1996. Straightforward statistics for the behavioral sciences. Brooks/Cole Pub. Co., Pacific Grove.

Ferretti, A., Fumagalli, A., Novali, F., Prati, C., Rocca, F., Rucci, A., 2011. A New Algorithm for Processing Interferometric Data-Stacks: SqueeSAR. IEEE Transactions on Geoscience and Remote Sensing, 49, 3460-3470.

Ferretti, A., Prati, C., Rocca, F., 2000. Nonlinear subsidence rate estimation using permanent scatterers in differential SAR interferometry. IEEE Transactions on Geoscience and Remote Sensing, 38, 2202-2212.

Gamba, P., Dell'acqua, F., Houshmand, B., 2003. Comparison and fusion of LIDAR and InSAR digital elevation models over urban areas. International Journal of Remote Sensing, 24, 4289-4300.

Gamba, P., Dell, Acqua, F., Lisini, G., Cisotta, F., 2006. Improving Building Footprints in InSAR Data by Comparison with a Lidar DSM. Photogrammetric Engineering \& Remote Sensing, 72, 63-70.

Gargoum, S.A., El-Basyouny, K., Froese, K., Gadowski, A., 2018. A Fully Automated Approach to Extract and Assess Road Cross Sections From Mobile LiDAR Data. IEEE Transactions on Intelligent Transportation Systems, 1-10.

Gernhardt, S., Adam, N., Eineder, M., Bamler, R., 2010. Potential of very high resolution SAR for persistent scatterer interferometry in urban areas. Annals of GIS, 16, 103-111.
Guan, H., Li, J., Cao, S., Yu, Y., 2016. Use of mobile LiDAR in road information inventory: a review. International Journal of Image and Data Fusion, 7, 219-242.

Hengl, T., 2006. Finding the right pixel size. Computers \& Geosciences, 32, 1283-1298.

Hilley, G.E., Bürgmann, R., Ferretti, A., Novali, F., Rocca, F., 2004. Dynamics of Slow-Moving Landslides from Permanent Scatterer Analysis. Science, 304, 1952-1955.

Hooper, A., 2010. A statistical-cost approach to unwrapping the phase of InSAR time series, Proceeding of International Workshop on ERS SAR Interferometry.

Kumar, P. and Angelats, E., 2017. AN AUTOMATED ROAD ROUGHNESS DETECTION FROM MOBILE LASER SCANNING DATA. Int. Arch. Photogramm. Remote Sens. Spatial Inf. Sci., XLII-1/W1, 91-96.

Lan, H., Li, L., Liu, H., Yang, Z., 2012. Complex Urban Infrastructure Deformation Monitoring Using High Resolution PSI. IEEE Journal of Selected Topics in Applied Earth Observations and Remote Sensing, 5, 643-651.

Lanari, R., Berardino, P., Bonano, M., Casu, F., Manconi, A., Manunta, M., Manzo, M., Pepe, A., Pepe, S., Sansosti, E., Solaro, G., Tizzani, P., Zeni, G., 2010. Surface displacements associated with the L'Aquila $2009 \mathrm{Mw} 6.3$ earthquake (central Italy): New evidence from SBAS-DInSAR time series analysis. Geophysical Research Letters, 37.

Lanari, R., Mora, O., Manunta, M., Mallorqui, J.J., Berardino, P., Sansosti, E., 2004. A small-baseline approach for investigating deformations on full-resolution differential SAR interferograms. IEEE Transactions on Geoscience and Remote Sensing, 42, 1377-1386.

Manunta, M., Marsella, M., Zeni, G., Sciotti, M., Atzori, S., Lanari, R., 2008. Two-scale surface deformation analysis using the SBAS-DInSAR technique: a case study of the city of Rome, Italy. International Journal of Remote Sensing, 29, 1665-1684.

Marsella, M., D'Aranno, P.J.V.D., Scutti, M., Scifoni, S., Sonnessa, A., González, E.J.L., Bonano, M., Manunta, M., Pepe, A., Ojha, C., 2015. Quantifying the effects of ground settlement on buildings by the exploitation of long term DINSAR time series: The case of Roma, 2015 IEEE 15th International Conference on Environment and Electrical Engineering (EEEIC), 2226-2230.

Marsella, M. and Scaioni, M., 2018. Sensors for Deformation Monitoring of Large Civil Infrastructures. Sensors, 18, 3941.

Massonnet, D. and Feigl, K.L., 1998. Radar interferometry and its application to changes in the Earth's surface. Reviews of Geophysics, 36, 441-500.

Milillo, P., Giardina, G., DeJong, M.J., Perissin, D., Milillo, G., 2018. Multi-Temporal InSAR Structural Damage Assessment: The London Crossrail Case Study. Remote Sensing, 10, 287.

Pepe, A. and Calò, F., 2017. A Review of Interferometric Synthetic Aperture RADAR (InSAR) Multi-Track Approaches 
for the Retrieval of Earth's Surface Displacements. Applied Sciences, 7, 1264.

Prochazka, D., Prochazkova, J., Landa, J., 2018. Automatic lane marking extraction from point cloud into polygon map layer. European Journal of Remote Sensing, 1-14.

Puente, I., González-Jorge, H., Riveiro, B., Arias, P., 2013. Accuracy verification of the Lynx Mobile Mapper system. Optics \& Laser Technology, 45, 578-586.

Qin, X., Zhang, L., Ding, X., Liao, M., Yang, M., 2018. Mapping and Characterizing Thermal Dilation of Civil Infrastructures with Multi-Temporal X-Band Synthetic Aperture Radar Interferometry. Remote Sensing, 10, 941.

Ragnoli, A., De Blasiis, M.R., Di Benedetto, A., 2018. Pavement Distress Detection Methods: A Review. Infrastructures, 3, 58.

Ruiz-Armenteros, A.M., Lazecky, M., Hlaváčová, I., Bakoň, M., Delgado, J.M., Sousa, J.J., Lamas-Fernández, F., Marchamalo, M., Caro-Cuenca, M., Papco, J., Perissin, D., 2018. Deformation monitoring of dam infrastructures via spaceborne MT-InSAR. The case of La Viñuela (Málaga, southern Spain). Procedia Computer Science, 138, 346-353.

Sansosti, E., Casu, F., Manzo, M., Lanari, R., 2010. Spaceborne radar interferometry techniques for the generation of deformation time series: An advanced tool for Earth's surface displacement analysis. Geophysical Research Letters, 37.

Schulz, T., 2008. Calibration of a terrestrial laser scanner for engineering geodesy. Institut für Geodäsie und Photogrammetrie an der Eidgenössischen Technischen Hochschule Zürich.

Scifoni, S., Bonano, M., Marsella, M., Sonnessa, A., Tagliafierro, V., Manunta, M., Lanari, R., Ojha, C., Sciotti, M., 2016. On the joint exploitation of long-term DInSAR time series and geological information for the investigation of ground settlements in the town of Roma (Italy). Remote sensing of environment, 182, 113-127.

Soergel, U., Cadario, E., Thiele, A., Thoennessen, U., 2008. Feature Extraction and Visualization of Bridges Over Water From High-Resolution InSAR Data and One Orthophoto. IEEE Journal of Selected Topics in Applied Earth Observations and Remote Sensing, 1, 147-153.

Tapete, D., Casagli, N., Luzi, G., Fanti, R., Gigli, G., Leva, D., 2013. Integrating radar and laser-based remote sensing techniques for monitoring structural deformation of archaeological monuments. Journal of Archaeological Science, 40, 176-189.

Terranova, C., Ventura, G., Vilardo, G., 2015. Multiple causes of ground deformation in the Napoli metropolitan area (Italy) from integrated Persistent Scatterers DinSAR, geological, hydrological, and urban infrastructure data. Earth-Science Reviews, 146, 105-119.

Tizzani, P., Battaglia, M., Zeni, G., Atzori, S., Berardino, P., Lanari, R., 2009. Uplift and magma intrusion at Long Valley caldera from InSAR and gravity measurements. Geology, 37, 63-66.

Torr, P.H.S. and Zisserman, A. (1996) MLESAC: A new robust estimator with application to estimating image geometry. Computer Vision and Image Understanding 78(1): 138-156.

Trasatti, E., Casu, F., Giunchi, C., Pepe, S., Solaro, G., Tagliaventi, S., Berardino, P., Manzo, M., Pepe, A., Ricciardi, G.P., Sansosti, E., Tizzani, P., Zeni, G., Lanari, R., 2008. The 2004-2006 uplift episode at Campi Flegrei caldera (Italy): Constraints from SBAS-DInSAR ENVISAT data and Bayesian source inference. Geophysical Research Letters, 35.

Werner, C., Wegmuller, U., Strozzi, T., Wiesmann, A., 2003. Interferometric point target analysis for deformation mapping, IGARSS 2003. 2003 IEEE International Geoscience and Remote Sensing Symposium. Proceedings (IEEE Cat. No.03CH37477), 4362-4364 vol.4367.

Williams, K., Olsen, M.J., Roe, G.V., Glennie, C., 2013. Synthesis of Transportation Applications of Mobile LIDAR. Remote Sensing, 5, 4652.

Yadav, M., Singh, A.K., Lohani, B., 2018. Computation of road geometry parameters using mobile LiDAR system. Remote Sensing Applications: Society and Environment, 10, 18-23.

Yang, C.-S., Kao, S.-P., Lee, F.-B., Hung, P.-S., 2004. Twelve different interpolation methods: A case study of Surfer 8.0, Proceedings of the XXth ISPRS Congress, 778-785.

Yen, K.S., Ravani, B., Lasky, T.A., 2011. LiDAR for data efficiency. Washington (State). Dept. of Transportation. Office of Research and Library Services.

Ying, W. and Qinfen, Z., 1995. Recognition of roads and bridges in SAR images, Proceedings International Radar Conference, 399-404.

Zeni, G., Bonano, M., Casu, F., Manunta, M., Manzo, M., Marsella, M., Pepe, A., Lanari, R., 2011. Long-term deformation analysis of historical buildings through the advanced SBAS-DInSAR technique: The case study of the city of Rome, Italy. Journal of Geophysics and Engineering, 8, S1S12. 